\title{
COMUNICACIÓN
}

\section{SEROPREVALENCIA DEL VIRUS DE LEUCOSIS BOVINA EN LA CUENCA LECHERA DE AREQUIPA}

\author{
Alicia Flores A. ${ }^{1}$ y Hermelinda Rivera G. ${ }^{2}$
}

\section{Whyore:}

\begin{abstract}
The seroprevalence of bovine leucosis virus (BLV) in 261 dairy herds from 8 different areas of the Arequipa valley in southern Peru was evaluated. A total of 410 blood samples were tested for antibodies against BLV utihizing indirect ELISA test and seroprevalence was found to be $12.8 \%(52 / 410)$ with $14.6 \%(38 / 261)$ of the herds infected. Seroprevalence was higher in the larger herds suggesting that management practice contributes to increased risk of viral transmission. The overall seroprevalence of BLV is low, making eradication of this disease in the Arequipa valley feasible.

Key words: Cattle, bovine leucosis virus, antibodies, ELISA.

Palabras clave: Bovinos, virus de la leucosis bovina, anticuerpos, ELISA.
\end{abstract}

La cuenca lechera de Arequipa cuenta con una población de 66,200 bovinos que está en manos de pequeños y medianos ganaderos y cuyo tipo de crianza es semiextensiva. La producción lechera es de 8 a $10 \mathrm{~L} /$ dia y con una producción anual de 162049 tm de leche (INEI, 1994) contribuyendo con la mayor producción de proteína de origen animal a la población del país. Como en todo el mundo el desarrollo de la industria lechera se ve limitada por un conjunto de factores siendo una de ellos las enfermedades infecciosas principalmente de origen viral y bacteriano.

La leucosis enzoótica bovina o leucemia o linfosarcoma bovina es una enfermedad producida por el virus de la Leucosis Bovina (VLB), un retrovirus, que conjuntamente con los virus linfotrópicos HTLV-I y HTLV-II, que afectan al humano,

\footnotetext{
${ }^{1}$ Práctica privada

${ }^{2}$ Laboratorio de Microbiología - IVITA - FMVUNMSM. E.mail:dl70029@unmsm.edu.pe
}

y el STLV, al simio, pertenecen al Subgrupo HTLV/BLV de la familia Retroviridae por compartir muchas de sus características biológicas (Fetchner et al., 1997; Schwartz y Levy, 1994; Ban et al., 1993).

El VLB es transmitido por contacto con la sangre de un animal infectado a otro susceptible, por aerosol o ingestión de leche. La manifestación clínica de la enfermedad es mayormente entre los 4 a 8 años de edad (Floss y Randle, 1993), el virus presenta un marcado tropismo por los linfocitos B circulantes del bovino al cual se adhiere a través de la glicoproteína 51 presente en la envoltura viral (Ban et al., 1993). La mayoría de los animales infectados con el VLB permanecen clínicamente normales pero desarrollan anticuerpos contra el virus sin otra evidencia de la infección, una tercera parte pueden desarrollar un incremento en número de linfocitos B circulantes denominado linfocitosis persistente y anticuerpos contra el virus y un 0.1 a $10 \%$ pueden desarrollar la forma tumoral denominado linfosarcoma (Darcel, 1996, Pyeon et al., 
1996). Los animales que desarrollan tumores pueden presentar diversos signos clínicos dependiendo de la ubicación del tumor (Floss y Randle, 1993).

Estudios de seroprevalencia efectuados en el Perú, han demostrado que esta enfermedad es enzoótica sobre todo en bovinos lecheros (Hung, 1983, Manchego et al., 1996) y recientes estudios evidencian un incremento en la prevalencia viral en los bovinos de las cuencas lecheras de Lima y Cajamarca (Rivera $\mathrm{H}$, datos no publicados) posiblemente debido a la falta de control. Siendo la cuenca lechera de Arequipa una de las principales áreas ganaderas y existiendo poca información disponible de la Leucosis enzoótica bovina en los animales lecheros, se tuvo especial interés en realizar el presente estudio considerando no solo un mayor número de animales, sino también un mayor número de áreas de esta importante cuenca lechera.

El presente trabajo fue realizado con muestras de vacas adultas de los sectores de Majes, La Joya, Santa Rita, El Cural, Zamácola, Islay, Vitor y Chuguata ubicados en las provincias de Caylloma, Arequipa e Islay. Estos sectores cuentan con 43560 bovinos lecheros en su mayoría raza Holstein criadas en forma semiextensiva y con pasturas cultivadas (Ministerio de Agricultura, 1996).

Las muestras de suero fueron seleccionadas aleatoriamente del banco de sueros de bovinos existentes en el Laboratorio de Virología de la Facultad de Medicina Veterinaria de la Universidad Nacional Mayor de San Marcos obtenidas de 261 hatos lecheros en 1998. El tamaño de la muestra fue en base al $27 \%$ de prevalencia del VLB obtenido en uno de los sectores (Manchego et al., 1996) con un nivel de confianza del $95 \%$.

Los anticuerpos fueron detectados mediante la prueba de ELISA indirecta proporcionada por la Agencia Internacional de Energía Atómica con una sensibilidad y especificidad de 96.5 y $96 \%$ respectivamente y según las indicaciones del manual del kit.

La seroprevalencia del VLB en las muestras de los 8 sectores se expresan en el Cuadro 1 , observándose una prevalencia aparente de $12.8 \%(52 / 410)$ y una prevalencia corregida de $9.5 \%$. En el Cuadro 2 , se indican las prevalencias del virus según los sectores de procedencia de las muestras. De los 261 hatos muestreados el $14.6 \%(38 / 261)$ estuvieron infectados con el VLB.

Cuadro 1. Seroprevalencia del virus de leucosis bovina en animales de la cuenca lechera de Arequipa mediante la prueba de ELISA indirecta.

\begin{tabular}{lccc}
\hline Sector & $\begin{array}{c}\text { Muestras, } \\
\mathrm{n}\end{array}$ & $\begin{array}{c}\text { Positivos, } \\
\mathrm{n}\end{array}$ & $\begin{array}{c}\text { Prevalencia, } \\
\%\end{array}$ \\
\hline Sta Rita & 82 & 17 & $20.7 \pm 8.8$ \\
El Cural & 29 & 4 & $13.8 \pm 12.6$ \\
La Joya & 29 & 3 & $10.3 \pm 11.1$ \\
Vitor & 28 & 4 & $14.3 \pm 13.0$ \\
Islay & 42 & 4 & $9.5 \pm 9.0$ \\
Zamácola & 61 & 12 & $19.7 \pm 10.0$ \\
Majes & 113 & 8 & $7.1 \pm 4.3$ \\
Chiguata & 26 & 0 & 0 \\
\hline Total & 410 & 52 & $12.8 \pm 3.2$ \\
\hline
\end{tabular}


Cuadro 2. Número de hatos infectados con el virus de leucosis bovina en los sectores muestreados mediante la prueba de ELISA indirecta.

\begin{tabular}{lccc}
\hline Sector & \multicolumn{2}{c}{ Hatos } & $\begin{array}{c}\text { Prevalencia, } \\
\%\end{array}$ \\
\cline { 2 - 3 } & Muestreados & Infectados & $45.0 \pm 21.8$ \\
Sta Rita & 20 & 9 & $15.0 \pm 15.6$ \\
El Cural & 20 & 3 & $16.6 \pm 17.2$ \\
La Joya & 18 & 3 & $15.0 \pm 15.3$ \\
Vitor & 21 & 3 & $9.5 \pm 8.9$ \\
Islay & 42 & 4 & $37.5 \pm 19.4$ \\
Zamácola & 24 & 9 & $7.2 \pm 5.1$ \\
Majes & 97 & 7 & 0.0 \\
Chiguata & 19 & 0 & $14.6 \pm 4.3$ \\
\hline Total & 261 & 38 &
\end{tabular}

El $12.8 \%(52 / 410)$ de las vacas adultas tuvieron anticuerpos contra el VLB. Similares estudios realizados en otras cuencas lecheras como Lima y Cajamarca determinaron prevalencias del VLB superiores al $50 \%$ (H Rivera datos no publicados), el presente resultado $(12.8 \%)$ es sorprendente teniendo en cuenta la falta de control de la enfermedad y la ausencia de restricción por parte de las autoridades sanitarias para la importación de animales.

La distribución de la prevalencia del VLB en los animales de los sectores muestreados fluctuó entre $20.7 \%$ que correspondieron al sector de Santa Rita y $7.1 \%$ como el más bajo en el sector de Majes (Cuadro 1). La diferencia más saltante entre ambos sectores es que en Santa Rita hay hatos con más de 50 vacas mientras que en Majes la mayoría de los hatos no poseen más de 10 animales. Los sectores de Santa Rita (45\%) y Zamacola (37.5\%) tuvieron el mayor número de hatos infectados, es posible que estos sectores recibieron más frecuentemente animales importados de otros países o de lugares con alta prevalencia y/o estuvieron afectos a otros factores de manejo que sumados a un mayor número de animales infectados estarían propiciando una mayor transmisión viral como lo indica Jimenez et al.(1995).
Algunas de las razones de la baja prevalencia del VLB en la cuenca lechera estudiada además de las mencionadas arriba, podrían ser la crianza de tipo semiextensiva donde los animales son confinados sólo en las noches disminuyendo la oportunidad de contagio (Villouta et al., 1994); así como al reducido número de animales por hato como ocurre en Majes y la restricción en la importación de animales infectados (SENASA, Ministerio de Agricultura). Actualmente esta última restricción se esta ejecutándo dentro del territorio nacional para evitar la introducción de animales infectados a áreas libres de la sierra.

Algunos estudios han demostrado que la VLB causa un deterioro del sistema inmune del animal incrementando la susceptibilidad a otras infecciones como mastitis, diarreas, neumonías, disminución de la producción lechera en 2.5 a $3 \%$ a nivel de hato y pérdidas por decomisos de carcasas por la presencia de tumor. A estas pérdidas se pueden sumar los costos por diagnóstico y servicio veterinario (OIE, 1996; Wells et al., 1996; Pelzer, 1997) por lo que es necesario conocer la actual situación epidemiológica de esta enfermedad a nivel nacional para recomendar medidas de control sobre todo en áreas de baja prevalencia como Arequipa en donde podría ser factible el desarrollo de 
un programa voluntario de control adoptando medidas correctivas de manejo, no introducción de animales positivos al hato y la eliminación progresiva de animales positivos de modo que, a corto o mediano plazo, se logre la erradicación de la Leucosis enzoótica bovina en la cuenca lechera de Arequipa.

La prueba de ELISA utilizada en el presente estudio posee una alta sensibilidad y especificidad (Anónimo, 1995) y detecta el isotipo de Ig GI o Ig M dependiendo del tipo de conjugado que se emplea. Esta prueba es muy útil para estudios epidemiológicos, puede analizar simultáneamente muchas muestras resultando más práctica y barata que las pruebas de radioinmunoensayo e inmunodifusión (Islas et al., 1996).

Por último, Yoshikawa et al. (1997) demostraron que vacas positivas a Leucosis bovina con mastitis subclínica eliminan numerosos linfocitos de la glándula mamaria infectados con el VLB por lo que se debe cortar consumir leche cruda que contenga linfocitos capaces de producir partículas virales, aun cuando el VLB no es considerado una zoonosis.

\section{Miteraturemint}

1. Anónimo. 1995. Informe final del Proyecto de Cooperación Técnica PER5020. Aplicación del inmunoanálisis en el estudio de las enfermedades de los animales. $25 \mathrm{p}$

2. Ban, J.; C. Portetelle; C. Altaner; B. Horion; D. Milan; V. Rahnak; A. Burny y R. Kettmann. 1993. Isolation and characterization of a $2.3 \mathrm{Kbp}$ cDNA fragment encoding the binding domain of the bovine leukemia virus cell receptor. J Virol. 67:1050-1057.

3. Darcel, C. 1996. A collection of assays on comparative medicine and a bibliography of references to the ELISA test. Ralliser Animal Health Laboratories Ltd. Lethbrige, Alberta Canadá. p91-98.

4. Fechner, H.; P. Blankenstein; A.
Looman; J. Elwert; L. Geue; C. Albrecht; A. Kurg; D. Beier; $O$. Marquardt y D. Ebner. 1997. Provirus variants of bovine leukemia virus and their relation to the serological status of naturally infected cattle. J Virol. 237:261269.

5. Floss, $J$ y R. Randle. 1993. Bovine leukosis. Agricultural Publication. College of Veterinary Medicine, University of Missouri, Columbia, USA. p4.

6. Hung, A. 1983. Bovine leukemia virus infection in Peru. Trop Anim Hlth Prod.15: 61.

7. III Censo Nacional Agropecuario. 1994. Instituto Nacional de Estadística e Informática (INEI). 525p.

8. Islas, A.; J. López; G. Montes y K. Rojas. 1996. Leucosis enzoótica bovina: inducción experimental de la infección con dos fuentes de virus. Arch Med Vet 28 (1): $117-124$.

9. Jiménez, $C$; J. Bonilla; G. Dolz; L. Rodríguez; L. Herrera; E. Bolaños; $M$. Cortez y E. Moreno. 1995. Bovine leukemia virus infection in Costa Rica. $J$ Vet Med. 42: 385-390.

10. Manchego, A.; N. Sandoval; A. Gonzáles; H. Rivera y R. Rosadio. 1996. Comparación de ELISA e inmunodifusión para el diagnóstico de leucosis bovina. Resúmenes del XIII Congreso Nacional de Ciencias Veterinarias. Lima, Perú.

11. Ministerio de Agricultura, Perú. 1996. Producción Pecuaria e Industria Avícola. Presidencia de la República, documento de consulta.

12. Office International of Epizooties (OIE). 1996. Manual of standards for diagnostic test and vaccines. 3th Edition $723 p$. World Organization for Animal Health. Paris, Francia.

13. Pelzer, K. 1997. Economics of bovine leukemia virus infection. Food Anim Retroviruses. 13 (1): 129-141.

14. Pyeon, D.; L. Oreilly y G Splitter. 1996. Increased interleukin-10 mRNA expression in tumor-bearing of persistently lymphocytotic animals 
infected with leukemia virus. J Virol. 70 (8): 5706-5710.

15. Schwartz, I. y D. Levy. 1994. Pathobiology of bovine leukemia virus. Vet Res. 25: 521-536.

16. Wells, D.; R. Alstad; R. Johnson y C. Kopral. 1996. High prevalence of bovine leukosis virus in U.S. dairy herds. HAHMS. 17. Villouta, G; Y. Durand; W. Cesped y
G. Montes. 1994. Dinámica de la infección con el virus de la leucosis bovina en un predio lechero de Chile. Arch Med Vet. 26 (2): 63-73.

18. Yoshikawa, H.; B. Xie; A. Oyamada y T. Yoshikawa. 1997. Detection of bovine leukemia viruses (BLV) in mammary tissues of BLV-antibody positive cows affected by subclinical mastitis. J Vet Med Sci. 59 (40: 301-302. 